\title{
Effects of coronary artery bypass grafting on left ventricular function assessed by multiple gated ventricular scintigraphy
}

\author{
N C TAYLOR, R W BARBER, P CROSSLAND, T A H ENGLISH, E P WRAIGHT, M C PETCH \\ From the Regional Cardiac Unit, Papworth Hospital, Cambridge; and Department of Nuclear Medicine, \\ Addenbrooke's Hospital, Cambridge
}

SUMMARY The effect of coronary artery bypass grafting on global left ventricular ejection fraction and regional contraction was studied in 56 consecutive patients with chronic stable angina pectoris by means of multiple gated ventricular scintigraphy at rest and during dynamic supine exercise before and six weeks after myocardial revascularisation.

Before operation, exercise induced a significant fall in ejection fraction and regional wall motion score. Six weeks after operation 52 patients were symptomless. Resting ejection fraction and regional wall motion score were unchanged but during exercise ejection fraction increased significantly, and the previous exercise induced regional wall motion abnormalities were abolished. All four patients with persisting angina showed the same pattern as before operation, with a fall in left ventricular ejection fraction and regional wall motion score during exercise.

Multiple gated ventricular scintigraphy affords a safe, objective, reproducible, and non-invasive means of assessing serial ventricular function at rest and during exercise in patients with ischaemic heart disease. The technique confirms that coronary bypass surgery abolishes exercise induced abnormalities of left ventricular function, but has no influence on resting function.

Coronary artery bypass grafting is now an established form of treatment for patients with chronic stable angina pectoris refractory to medical treatment. ${ }^{12}$ The operation carries a low mortality and relieves angina in approximately $85 \%$ of patients after surgery. ${ }^{34}$ Despite a decrease in symptoms and objective improvement in exercise tolerance as shown by treadmill testing, ${ }^{56}$ symptomatic relief of pain does not necessarily imply improved coronary blood flow. Intraoperative infarction and even a placebo effect may be responsible for relief of symptoms. ${ }^{4}$

The previously reported effects of coronary artery surgery on left ventricular function are conflicting. Some studies have shown little or no improvement and even deterioration in ventricular function. ${ }^{7-10}$ Conversely others have shown improvement after operation in patients with preoperative exercise induced ventricular dysfunction. ${ }^{11-13}$ This variability may in part be because most studies have assessed left ventricular function only at rest and included data

Accepted for publication 9 May 1983 obtained at varying times after operation, an important factor that has previously been stressed. ${ }^{14}$ Additionally, the invasive methods used are not well suited to routine serial postoperative evaluation in a large group of patients.

Multiple gated ventricular scintigraphy can be used to assess cardiac function not only at rest but during exercise. ${ }^{15}$ It is safe, reproducible, inexpensive, and highly suited to serial investigation 1617 before and after operation. The purpose of this prospective study was to examine, by means of multiple gated ventricular scintigraphy, left ventricular ejection fraction and regional wall movement both at rest and during dynamic supine exercise before and six weeks after myocardial revascularisation; and to correlate these findings with the symptomatic state of the patient.

Patients and methods

PATIENT POPULATION

Fifty-six consecutive patients with chronic stable angina pectoris, after routine investigation and accep- 
tance for myocardial revascularisation, were studied before and six weeks after operation. There were no operative deaths and all 56 were available for follow up. Fifty-two were men, with a mean age of 54.4 years, four were women with a mean age of 54.8 years. No patient had sustained a myocardial infarction within six months of investigation, though 29 (51.8\%) had previous myocardial infarctions documented by serial electrocardiographic and/or enzymatic changes.

Forty-six patients had severe proximal triple vessel disease including six patients with left main stenosis. Six had proximal two vessel disease and three had single vessel disease.

The drug treatment before and after operation is shown in the Table. All patients were investigated before operation while continuing beta blocker therapy because of their severe symptoms, and the risk of arrhythmias, exacerbation of angina, or infarction on sudden withdrawal. ${ }^{18-20}$

Table Drug treatment before and afier operation

\begin{tabular}{lcc}
\hline & Before operation & $\begin{array}{l}\text { Six weeks after } \\
\text { operation }\end{array}$ \\
\hline Beta Blockers & 54 & 1 \\
Calcium antagonists & 25 & 0 \\
Long acting nitrates & 13 & 0 \\
Warfarin & 3 & 21 \\
Digoxin & 0 & 18 \\
Diuretics & 4 & 37 \\
Verapamil & 0 & 3 \\
Perhexiline & 2 & 0 \\
\hline
\end{tabular}

MULTIPLE GATED VENTRICULAR SCINTIGRAPHY Multiple gated ventriculography based on standard techniques ${ }^{15}$ was performed on all patients at rest and during dynamic supine exercise. Autologous red blood cells labelled in vitro with $750 \mathrm{MBq}{ }^{99 m} \mathrm{Tc}$ by means of the Brookhaven National Laboratory Kit, were administered intravenously. After 10 minutes to allow for equilibration within the blood pool, data acquisition was performed in the supine position. A conventional small field of view single crystal gamma camera (Ohio-Nuclear Series 100) equipped with a medium sensitive parallel hole collimater was positioned over the patient in a modified left anterior oblique position in order to achieve maximum separation of both ventricles and left atrium. Imaging was started using a Varian V-77 computer and computer based electrocardiographic gating at 18 frames per cardiac cycle to a total of $31 / 2$ million counts, resulting in approximately 200000 counts per frame.

After the resting study, an exercise study was performed with the patient in the same position. Graded maximum exercise was performed by means of supine bicycle ergometry, mounted in a stable position from the end of the imaging table. Patient stability was maintained by means of adjustable shoulder supports. Imaging was started at the onset of symptoms, that is, angina, dyspnoea, fatigue, or electrocardiographic evidence of ischaemia ( $1 \mathrm{~mm}$ ST segment depression). Blood pressure was recorded at rest and at one minute intervals throughout the exercise study; heart rate and cardiac rhythm were monitored throughout. The study was terminated if angina became progressively severe or with the onset of haemodynamic deterioration or serious arrhythmia. The same symptom limited procedure was repeated six weeks after operation.

Ventricular function was assessed both in terms of global ejection fraction and abnormalities of regional contraction. Left ventricular ejection fraction was calculated as end-diastolic counts minus end-systolic counts divided by background corrected end-diastolic counts. This method employed separate end-diastolic and end-systolic left ventricular regions of interest, with background taken in the region given by the end-diastolic area minus the end-systolic area. This method in our own laboratory compares favourably with contrast angiography $(R=0.95)$. In keeping with work from our own laboratory and others ${ }^{17}$ resting left ventricular ejection fraction below 0.60 and less than $6 \%$ absolute increase in ejection fraction with exercise were considered abnormal. Left ventricular wall motion was assessed by reviewing the scintigraphic data in a closed loop cine format. Semiquantitative assessment was performed by dividing the left ventricle in the left anterior oblique position into five segments (Fig 1): proximal and distal septal, inferior, and proximal and distal posterolateral, each being assigned a value ranging from three for normal contraction to 0 and -1 for akinesia and paradoxical movement, respectively. The total regional wall motion score was obtained by summation of the segmental values.

\section{CORONARY ARTERY BYPASS SURGERY}

All 56 patients underwent saphenous vein bypass grafting. Myocardial protection was by means of cold cardioplegia and topical hypothermia together with

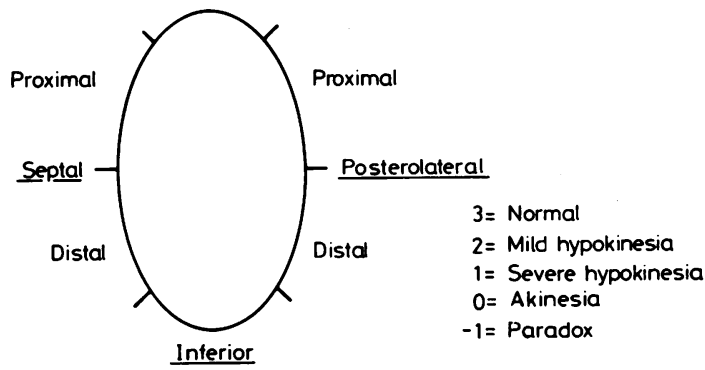

Fig. 1 Assessment of regional wall motion score from multiple gated ventriculography in the left anterior oblique position 
moderate systemic hypothermia $\left(30^{\circ} \mathrm{C}\right)$. One patient received five grafts, 22 had four, 22 had three, eight had two, and three had single grafts. The mean number of grafts per patient was $3 \cdot 2$. Mean bypass time was 107.6 minutes (range 42 to 178 minutes) and ischaemic time 63 minutes (range 19 to 85 minutes). No patient showed electrocardiographic evidence of perioperative infarction.

\section{STATISTICS}

All data are presented as arithmetic means \pm standard error of the mean. Differences were tested for significance by the paired $t$ test, and Wilcoxon rank sum test. $P$ values higher than 0.05 were not regarded as significant.
Results

PREOPERATIVE RADIONUCLIDE INVESTIGATIONS Before operation all patients were limited by angina. The mean resting left ventricular ejection fraction of all 56 patients was $0.65 \pm 0.02$ (range $0.83-0.33$ ). Ejection fraction was below 0.60 in 12 patients. During exercise no side effects or serious arrhythmias were encountered. Total work-load achieved was 2513 $\pm 132 \mathrm{kpm}$ and ejection fraction fell to $0.58 \pm 0.02$ (p $<0.001$ ) (Fig 2a). Left ventricular ejection fraction fell below 0.60 during exercise in 31 patients. Fortynine patients $(87.8 \%)$ had a fall in ejection fraction with exercise. Of the seven who did not, six had an increase of less than $3 \%$.
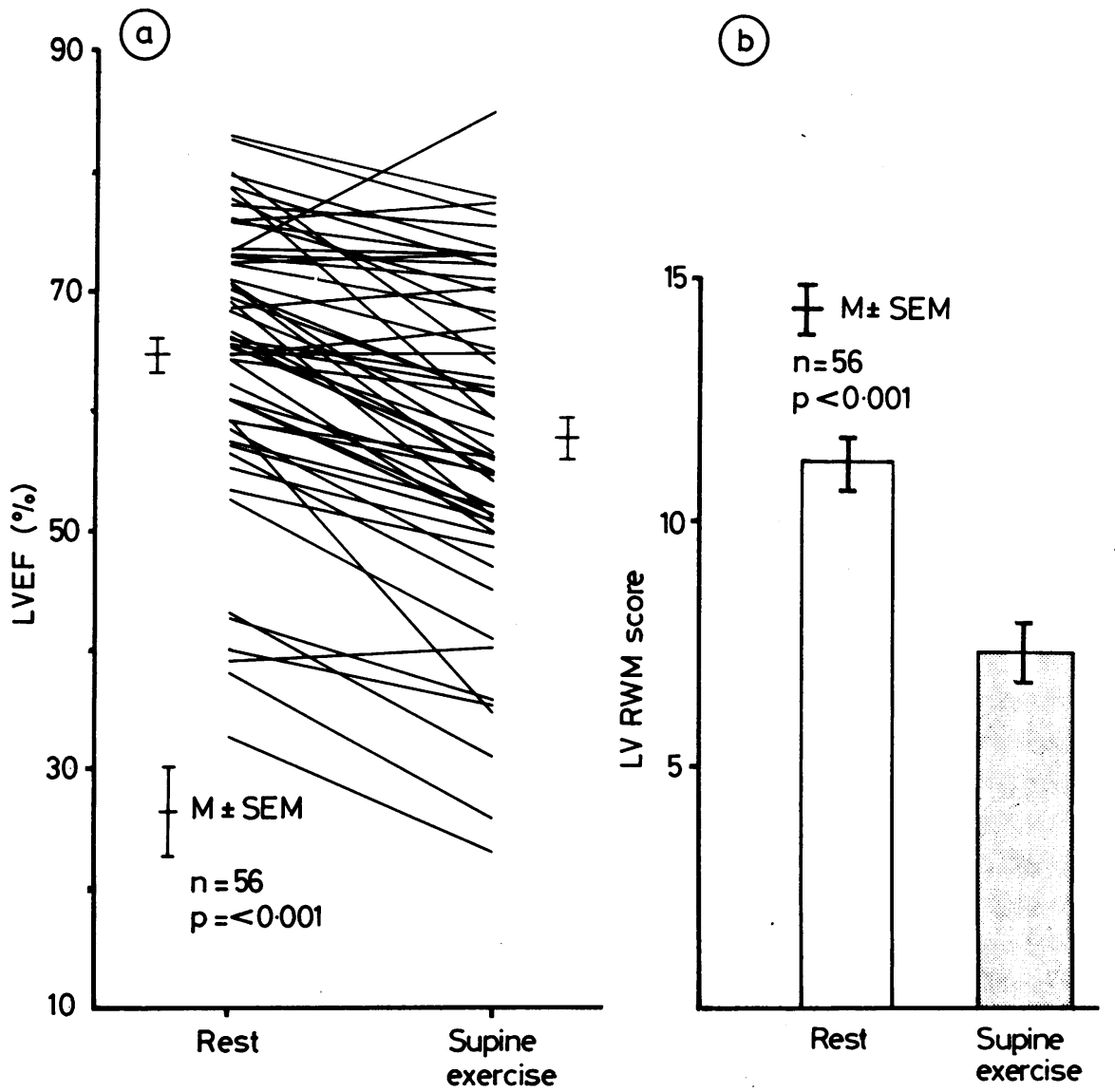

Fig. 2(a) Absolute change in left ventricular ejection fraction (LVEF) during exercise before coronary artery bypass grafting (CABG), expressed as a percentage; (b) change in regional wall motion score (RWS) during exercise before operation. 
The regional wall motion score at rest was $11.3 \pm$ 0.4 . It was normal in 15 patients. Thirteen patients had abnormalities of regional contraction in less than two segments, and 28 had abnormal wall motion in three or more segments examined. During exercise wall motion score fell to $7.4 \pm 0.5(p<0.001)$ (Fig 2b). Only three patients showed no deterioration of regional contraction with exercise. Two of these showed an abnormal global ventricular response to exercise, ejection fraction increased by only $2.7 \%$ in one, and showed a fall of $15.7 \%$ in the other.

\section{POSTOPERATIVE RADIONUCLIDE}

\section{INVESTIGATIONS-ASYMPTOMATIC PATIENTS}

Six weeks after operation 52 patients were asymptomatic and none had pain during exercise testing; they were stopped by fatigue. Some patients continued to receive medication as detailed in the Table. The total workload achieved increased to $4200 \pm 129$ $\mathrm{kpm}(\mathrm{p}<0.001$ ), representing an $89.8 \%$ increase compared with the preoperative workload. In the group as a whole resting ejection fraction was unchanged after operation, being $0.65 \pm 0.02$ before and $0.64 \pm 0.01$ after operation (Fig 3a). Three patients showed a fall in resting ejection fraction of less than 0.06 (range 0.06 to 0.23 ). Three patients showed an increase in resting ejection fraction (range 0.07 to 0.23 ); these had a preoperative resting value of less than 0.4 . The mean resting wall motion score was unchanged after operation, being $11.3 \pm 0.4$ before and $11.9 \pm 0.4$ after (Fig 3b). One patient showed an improved wall motion score from four to ten; he also showed a preoperative resting ejection fraction of only 0.33 which improved to 0.56 after operation.

During exercise there was an increase in ejection fraction from $0.64 \pm 0.01$ to $0.72 \pm 0.01$ $(p<0.001)$ (Fig 4a). No patient showed a fall in ejection fraction during exercise. Fourteen patients showed an increase in ejection fraction of less than 0.06 (range 0.01 to 0.04 ). The relative increase in ejection fraction with exercise after operation was $11.4 \pm$ $0.8 \%$ as compared with a fall of $10.9 \pm 1.4 \%$ before operation $(p<0.001)$ (Fig 5). Exercise abnormalities of regional contraction were abolished after, the mean wall motion score being 12.0 \pm 0.4 (Fig 4b).

The presence of previous myocardial infarction had no influence on these results.
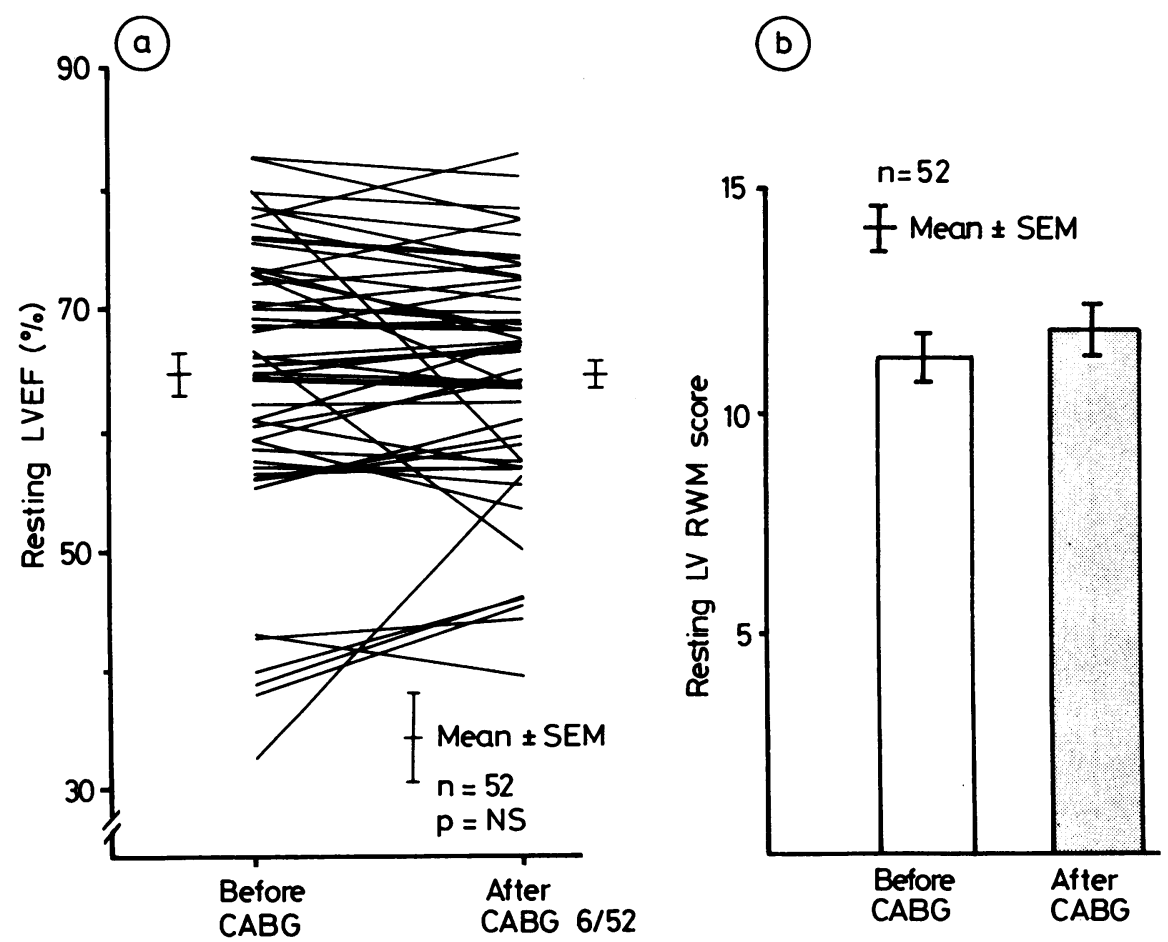

Fig. 3(a) Resting $L V E F$ before and after $C A B G$ in patients free of angina after operation expressed as a percentage; (b) resting $R W S$ before and after $C A B G$ in patients free of angina after operation. 


\section{POSTOPERATIVE RADIONUCLIDE} INVESTIGATIONS-SYMPTOMATIC PATIENTS

Four patients continued to experience exertional angina six weeks after operation. Three were male and one was female. During exercise the total workload achieved was marginally increased to $2295 \pm 424 \mathrm{kpm}$ contrasting with a preoperative workload of $1993 \pm$ $440 \mathrm{kpm}$ for this group. This failed to reach statistical significance $(p=0.2)$. The resting ejection fraction was $0.66 \pm 0.05$ before operation and $0.60 \pm 0.09$ after. All continued to show a fall in ejection fraction from a resting mean value of $0.60 \pm 0.90$ to $0.51 \pm$ 0.09 . Likewise all continued to show a relative fall in ejection fraction with exercise after operation with values of $13.5 \% \pm 6 \%$ before and $15.7 \% \pm 4 \%$ after. In this group two patients showed a greater relative fall after operation, one was unchanged, and one showed minimal improvement.

The resting wall motion score in this group was uninfluenced by operation being $11.5 \pm 0.9$ before and $11.3 \pm 0.8$ after; it fell in all patients during exercise to $7.5 \pm 1.3$ compared with $5.8 \pm 1.5$ before operation.

\section{Discussion}

During the past decade coronary bypass grafting has become an established form of treatment for patients with chronic stable angina refractory to medical treatment. At least $85 \%$ of patients are initially free of symptoms ${ }^{1421-23}$ and the operation is now associated with a low mortality rate. ${ }^{3}$ Though the symptomatic improvement may be secondary to improved myocardial perfusion of the previously ischaemic segments, it has been suggested that intraoperative infarction, or even placebo effect, may be responsible for this symptomatic relief. Despite the symptomatic improvement and the knowledge that graft patency is $90 \%$ at six weeks, ${ }^{1}$ objective evidence of improved cardiac function has been difficult to obtain because it is not always justifiable to restudy all patients by conventional contrast angiography electively. Comparison of treadmill testing before and after operation has shown postoperative reversal of a preoperative ischaemic ST response to exercise in over $50 \%$ of patients, but results remain inconclusive because false negative and indeterminate results are common. 56 Moreover, improved exercise tolerance after operation may be
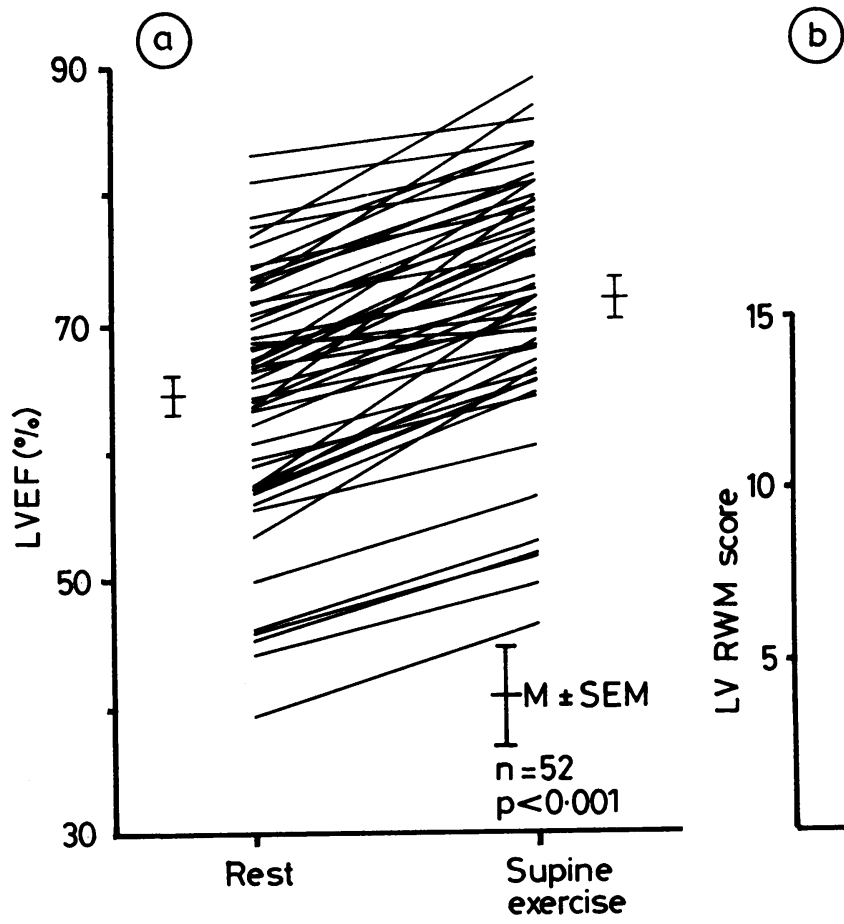

$$
\begin{aligned}
& \mp M \pm S E M \\
& n=52
\end{aligned}
$$

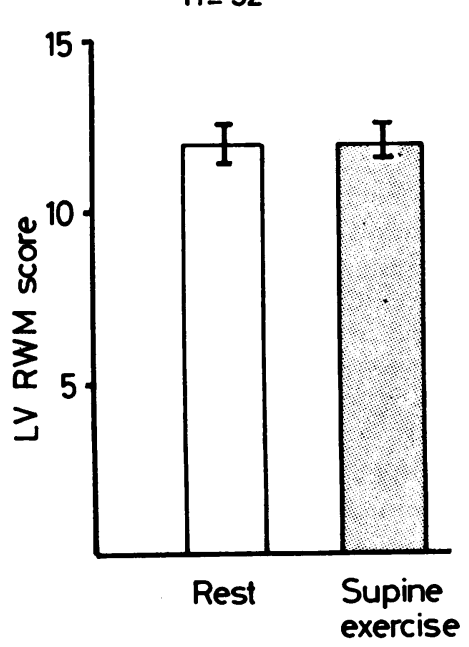

Fig. $4($ a) Absolute change in $L V E F$ during exercise after $C A B G$ in patients free of angina after operation, expressed as a percentage; (b) change in RWS during exercise after CABG in patients free of angina afier operation. 


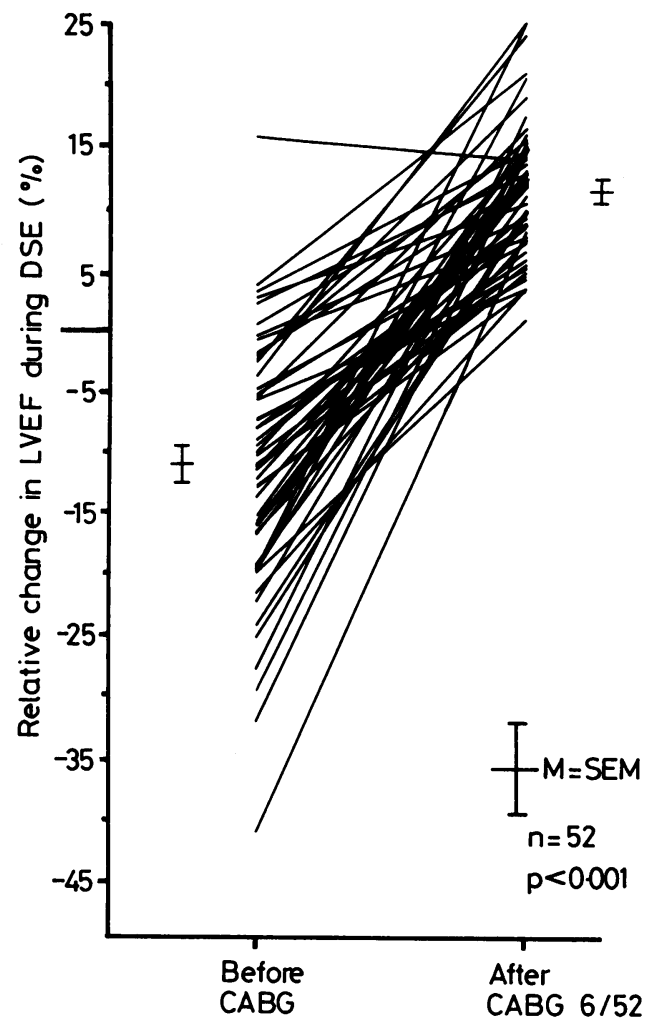

Fig. 5 Relative change in $L V E F$ during exercise before and after $C A B G$ in patients free of angina after operation (DSE, dymamic supine exercise)

influenced by improved motivation and training programmes. 2425

The previously reported effects of coronary surgery on left ventricular function are unsatisfactory for a variety of reasons. Many studies include postoperative results obtained at varying time intervals after revascularisation and have included results from the early postoperative period where pronounced sympathetic overactivity has been shown to be present; variations in adrenergic tone may influence ventricular function for at least two weeks after operation, or even longer. ${ }^{26}$ Often ventricular function has been studied only at rest. 1427 The use of contrast exercise ventriculography has been shown to be more valuable than resting studies alone in the evaluation of ventricular function, ${ }^{28}$ but despite its application after coronary surgery 1213 it is not suited to routine serial evaluation in a large group of patients. Multiple gated ventricular scintigraphy, both at rest and during exercise, overcomes these difficulties, providing a simple, precise, and reproducible technique ${ }^{29}{ }^{30}$; it has been shown to enable accurate assessment of ventricular function to be made in the presence of ischaemic heart disease. 153132 The advantages of our study are its prospective nature, the use of a non-invasive technique for the assessment of both resting and exercise ventricular function, and the standard time interval after operation for re-evaluation. Six weeks was chosen because we felt that any effect of surgery would largely have worn off by this time.

Patients with angina pectoris may have normal resting left ventricular function; exercise generally induces a fall, or less than normal increase, in global ejection fraction with the development of abnormal ventricular contraction within the ischaemic segments. ${ }^{73334}$ This is confirmed in our preoperative study group where $85 \%$ of patients showed a fall in exercise ejection fraction; only one of the remainder showed a normal increase of greater than 0.06. As well as global deterioration in ventricular function, impairment in regional contraction occurred in all but three patients.

While beta blockers may be of considerable benefit in some patients with heart disease, several studies have shown their negative inotropic effect. ${ }^{35} 36$ Their effect is most frequently seen, and may be most pronounced, in patients with impaired ventricular function, ${ }^{37} 38$ who depend upon an increased sympathetic drive to maintain cardiac output. The negative inotropic effect may even be dose related. ${ }^{39}$ In patients with ischaemic heart disease the reported effects of beta blockers are conflicting; but because these drugs bring about an improved balance between oxygen supply and demand they may actually improve myocardial contractility, despite their negative inotropic effect on non-ischaemic myocardium. Recent studies using radionuclide techniques have shown that beta blocking drugs have no detrimental effect on ventricular function in patients with ischaemic heart disease, even in those with ejection fractions of less than $0.40^{40}$; moreover, improvement has been reported..$^{41} 42$ In patients like ours it seems likely that beta blockade has little effect on resting ventricular function but it may inhibit exercise induced dysfunction. The fact that our patients continued to experience angina with a fall in left ventricular ejection fraction on exercise implies that the preoperative treatment was not fully effective. So we believe that treatment with beta blocking drugs had no significant influence on our results; had we risked stopping the drugs, then the only difference would have been the lower workloads achieved on exercise before operation.

At the postoperative study resting ejection fraction and regional contraction were unchanged; thus no significant myocardial damage had resulted, reflecting satisfactory methods of myocardial preservation..$^{43}$ The improvement in ejection fraction and regional 
contractility with exercise indicates that coronary surgery corrects the ischaemic response, shows that symptomatic improvement is the result of improved myocardial perfusion, and emphasises the importance of such an exercise study.

Our work confirms that radionuclide ventriculography is useful for assessing the improvement in exercise ventricular function that accompanies successful myocardial revascularisation in patients with ischaemic heart disease. Its objective nature makes it particularly helpful in patients whose symptoms are difficult to interpret.

\section{References}

1 McIntosh HD, Garcia JA. The first decade of aortocoronary bypass grafting, 1967-1977. Circulation 1978; 57: 405-31.

2 Hurst JW, King SB, Logue RB, et al Value of coronary bypass surgery. Am $\mathcal{F}$ Cardiol 1978; 42: 308-29.

3 Braunwald E. Coronary artery bypass surgery-an assessment. Postgrad Med F 1976; 52: 733-8.

4 Ross RS. Ischemic heart disease-an overview. Am $\mathfrak{f}$ Cardiol 1975; 36: 496-505.

5 Bartel AG, Behar VS, Peter RH, Orgain ES, Kong Y. Exercise stress testing in evaluation of aortocoronary bypass surgery. Circulation 1973; 48: 141-8.

6 Dodek A, Kassebaum DG, Griswold HE. Stress electrocardiography in the evaluation of aortocoronary bypass surgery. Am Heart f 1973; 86: 292-307.

7 Arboglast R, Solignac A, Bourassa MG. Influence of aortocoronary saphenous vein bypass surgery on left ventricular volumes and ejection fraction. Comparison before and one year after surgery in 51 patients. Am $\mathcal{J}$ Med 1973; 54: 290-6.

8 Wolf NM, Kreulen TH, Bove AA, et al. Left ventricular function following coronary bypass surgery. Circulation 1978; 58: 63-70.

9 Hammermeister KE, Kennedy JW, Hamilton GW, et al. Aortocoronary saphenous vein bypass - failure of successful grafting to improve resting left ventricular function in chronic angina. $N$ Engl F Med 1974; 290: 186-92.

10 Shepherd RL, Itscoitz SB, Glancy DL, et al. Deterioration of myocardial function following aorto-coronary bypass operation. Circulation 1974; 49: 467-75.

11 Barry WH, Pfeifer JF, Lipton MJ, Tilkian AG, Hultgren HN. Effects of coronary artery bypass grafting on resting and exercise hemodynamics in patients with stable angina pectoris: a prospective, randomized study. Am $\mathcal{f}$ Cardiol 1976; 37: 823-30.

12 Bussmann WD, Mayer V, Kober G, Kaltenbach M. Ventricular function at rest, during leg raising and physical exercise before and after aorto-coronary bypass surgery. Am ₹ Cardiol 1979; 43: 488-501.

13 Vliestra RE, Chesebro JH, Frye RL, Wallace RB. Improvement of left ventricular exercise hemodynamic function after aorta-coronary artery bypass grafting. $\mathcal{F}$ Thorac Cardiovasc Surg 1981; 81: 85-91.

14 Mintz LJ, Ingels NB, Jr Daughters GT, II Stinson EB,
Alderman EL. Sequential studies of left ventricular function and wall motion after coronary arterial bypass surgery. Am ₹ Cardiol 1980; 45: 210-6.

15 Borer JS, Bacharach SL, Green MV, Kent KM, Epstein SE, Johnston GS. Real time radionuclide cine angiography in the non-invasive evaluation of global and regional left ventricular function at rest and during exercise in patients with coronary-artery disease. $N$ Engl $\mathcal{F}$ Med 1977; 296: 839-44.

16 Marshall RC, Berger HJ, Reduto LA, Gottschalk A, Zaret BL. Variability in sequential measures of left ventricular performance assessed with radionuclide angiocardiography. Am f Cardiol 1978; 41: 531-6.

17 Jones RH, McEwan P, Newman GE, et al. Accuracy of diagnosis of coronary artery disease by radionuclide measurement of left ventricular function during rest and exercise. Circulation 1981; 64: 586-601.

18 Miller RR, Olson HG, Amsterdam EA, et al. Propranolol - withdrawal rebound phenomenon. N Engl f Med 1975; 293: 416-8.

19 Alderman EL, Coltart DJ, Wettach GE, Harrison DC. Coronary artery syndromes after sudden propranolol withdrawal. Ann Intern Med 1974; 81: 625-7.

20 Frishman WH, Christodoulou J, Weksler B, Smithen C, Killip T, Scheidt S. Abrupt propranolol withdrawal in angina pectoris: effects on platelet aggregation and exercise tolerance. Am Heart $\mathcal{F}$ 1979; 95: 169-79.

21 Selden R, Neill WA, Ritzmann LW, Okies JE, Anderson RP. Medical versus surgical therapy for acute coronary insufficiency. $N$ Engl f Med 1975; 293: 1329-33.

22 Gott VL. Outlook for patients after coronary artery revascularisation. Am $\mathcal{f}$ Cardiol 1974; 33: 431-7.

23 Anderson RP, Rahimtoola SH, Boncheck LI, Starr A. The prognosis of patients with coronary artery disease after coronary bypass operations. Time related prognosis of 532 patients with disabling angina pectoris. Circulation 1974; 50: 274-82.

24 Vatner SF, Pagani M. Cardiovascular adjustments to exercise: hemodynamics and mechanisms. Prog Cardiovasc Dis 1976; 19: 91-108.

25 Lapin ES, Murray JA, Bruce RA, Winterscheid L. Changes in maximal exercise performance in the evaluation of saphenous vein bypass surgery. Circulation 1973; 47: 1164-73.

26 Boudoulas H, Lewis RP, Vasko JS, Karayannacos PE, Beaver BM. Left ventricular function and adrenergic hyperactivity before and after saphenous vein bypass. Circulation 1976; 53: 802-6.

27 Zir LM, Dinsmore R, Vexeridis M, Singh JB, Harthorne JW, Daggett WM. Effects of coronary bypass grafting on resting left ventricular contraction in patients studied 1 to 2 years after operation. Am $\mathcal{F}$ Cardiol $1979 ; 44: 601-6$.

28 Sharma B, Goodwin JF, Raphael MJ, Steiner RE, Rainbow RG, Taylor SH. Left ventricular angiography on exercise: a new method of assessing left ventricular function in ischaemic heart disease. Br Heart $\mathcal{F}$ 1976; 38: 59-70.

29 Burow RD, Strauss HW, Singleton R, et al. Analysis of left ventricular function from multiple gated acquisition of cardiac blood pool imaging. Comparison to contrast angiography Circulation 1977; 56: 1024-8.

30 Brady TJ, Lo K, Thrall JH, Walton JA, Brymer JF, Pitt 
B. Exercise radionuclide ejection fraction: correlation with exercise contrast ventriculography. Radiology 1979; 132: 703-5.

31 Greenberg BH, Drew D, Botvinick EH, et al. Evaluation of left ventricular performance by gated radionuclide angiography. Clin Nucl Med 1979; 5: 245-54.

32 Borer JS, Kent KM, Bacharach Sl, et al. Sensitivity, specificity and predictive accuracy of radionuclide cineangiography during exercise in patients with coronary artery disease. Circulation 1979; 60: 572-80.

33 Jengo JA, Oren V, Conant B, et al. Effects of maximal exercise stress on left ventricular function in patients with coronary artery disease using first pass radionuclide angiocardiography. Circulation 1979; 59: 60-5.

34 Rerych SK, Scholz PM, Newman GE, Sabiston DC Jr, Jones $\mathbf{R} H$. Cardiac function at rest and during exercise in normals and in patients with coronary heart disease. Ann Surg 1978; 187: 449-64.

35 Dwyer EM, Weiner L, Cox JW. Effects of betaadrenergic blockade (propranolol) on left ventricular hemodynamics and the electrocardiogram during exercise induced angina pectoris. Circulation 1968; 38: 250 60.

36 Epstein SE, Braunwald E. Inhibition of the adrenergic nervous system in the treatment of angina pectoris. Med Clin North Am 1968; 52: 1031-9.

37 Coltart DJ, Alderman EL, Robison SC, Harrison DC. Effect of propranolol on left ventricular function, segmental wall motion, and diastolic pressure-volume relation in man. Br Heart $\mathcal{f}$ 1975; 37: 357-64.

38 Frishman WH. Beta-adrenoceptor antagonists: new
Taylor, Barber, Crossland, English, Wraight, Petch

drugs and new indications. $N$ Engl f Med 1981; 305: $500-6$.

39 Frishman W, Smithen C, Befler B, Kligfield P, Killip T. Non-invasive assessment of clinical response to oral propranolol therapy. Am $\mathcal{F}$ Cardiol 1975; 35: 635-44.

40 Dehmer GJ, Falkoff M, Lewis SE, Hillis LD, Parkey RW, Willerson JT. Effect of oral propranolol on rest and exercise left ventricular ejection fraction, volumes, and segmental wall motion in patients with angina pectoris. Assessment with equilibrium gated blood pool imaging. Br Heart f 1981; 45: 656-66.

41 Battler A, Ross J Jr, Slutsky R, Pfisterer M, Ashburn W, Froelicher V. Improvement of exercise induced left ventricular dysfunction with oral propranolol in patients with coronary heart disease. Am $\mathcal{f}$ Cardiol 1979; 44: 318-24.

42 Marshall RC, Wisenberg G, Schelbert HR, Henze E. Effect of oral propranolol on rest, exercise and postexercise left ventricular performance in normal subjects and patients with coronary artery disease. Circulation 1981; 63: 572-83.

43 Ellis RJ, Born M, Feit T, Ebert PA. Potassium cardioplegia. Early assessment by radionuclide ventriculography. Circulation 1978; 58 (suppl I): 57-61.

Requests for reprints to Dr N C Taylor, Regional Cardiac Unit, Papworth Hospital, Papworth Everard, Cambridge CB3 8RE. 